\title{
Dating biosignatures in fracture habitats of the deep igneous rock- hosted biosphere
}

\author{
MiKAEL TILLBERG ${ }^{1}$, HENRIK DRAKE $^{1}$, NiCK M.W.
} ROBERTS ${ }^{2}$, THOMAS ZACK ${ }^{3}$, MAGNUS IVARSSON ${ }^{4,5}$, Christine HeIM ${ }^{6}$, MARTIN WhitehOUSE ${ }^{4}$

${ }^{1}$ Department of Biology and Environmental Science, Linnaeus University, 39182 Kalmar, Sweden mikael.tillberg@lnu.se ; henrik.drake@lnu.se ${ }^{2}$ Geochronology and Tracers Facility, British Geological Survey, Environmental Science Centre, Nottingham, UK ${ }^{3}$ Department of Earth Sciences, Gothenburg University, Gothenburg, Sweden

${ }^{4}$ Swedish Museum of Natural History, Stockholm, Sweden ${ }^{5}$ Department of Biology, University of Southern Denmark, Odense, Denmark

${ }^{6}$ Department of Geobiology, Geoscience Centre, GeorgAugust University, Göttingen, Germany

The globally vast deep biosphere in crystalline rock aquifers is spatially confined to open space provided by fractures that offer pathways for water, gases, nutrients and organic carbon essential to sustain microbial life in this anaerobic and oligotrophic realm. Processes related to microbial metabolism, such as methanogenesis, anaerobic methane oxidation and bacterial sulphate reduction, cause $\delta^{13} \mathrm{C}$ and $\delta^{34} \mathrm{~S}$ fractionation recorded by authigenic calcite and pyrite precipitating on the fracture walls $[1,2]$.

Tiny growth zones of crystals in single fracture coatings can now be utilized to constrain the timing of the biological activity through high spatial resolution $\mathrm{U}-\mathrm{Pb}$ and $\mathrm{Rb}-\mathrm{Sr}$ geochronology combined with molecular biosignature and stable isotope analyses. Here we present this approach and discuss several recent findings disclosing discrete events of microbial activity within a wide time frame, from Devonian to Pliocene, and depths down to almost $1 \mathrm{~km}$ into fractured bedrock and ancient impact craters $[3,4]$.

Knowledge of the deep biosphere's development through deep time is still extremely scarce, despite that it may be the largest microbial habitat on our planet. Our biosignature dating protocol gives new insights into this history on Earth, with astrobiological implications.

References:

[1] Drake et al. (2017) EPSL 470, 108-118. [2] Drake et al.

(2018). Geobiol 16, 556-574. [3] Drake et al. (2019). Nat.

Comm 10, 4736. [4] Tillberg et al. (2019). Geosci, 9(5), 202. 